\title{
ORIGINAL
}

ARTICLES

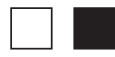

\section{Physician Attitudes and Self-reported Practices Toward Prostate Cancer Screening in Black and White Men}

Nicholas Shungu, MD, MPH; Vanessa Diaz, MD, MSCR; Suzanne Perkins, MPH; Ambar Kulshreshtha, MD, PhD

BACKGROUND AND OBJECTIVES: Updated 2018 prostate cancer screening guidelines recommend informed decision-making discussions, which should include education on prostate cancer's disproportionate impact on Black men. It is unknown whether academic family physicians follow these guidelines.

METHODS: Family physicians were surveyed as part of the 2020 Council of Academic Family Medicine Educational Research Alliance (CERA) survey. We used $\chi^{2}$ to compare physicians' knowledge and screening practices stratified by physician age, gender, and percentage of Black patients in patient panel. We calculated logistic regressions predicting shared decision-making conversations, barriers to shared decision-making, inclusion of race in prostate cancer screening approach, and prostate-specific antigen (PSA) testing adjusted for physician age, gender, and percentage of Black patients.

RESULTS: Physicians reported engaging in shared decision-making for prostate cancer screening in half of eligible men. Only $29.2 \%$ of physicians reported routinely informing Black men of their increased prostate cancer risk. In logistic regressions, physician gender (female) and fewer Black patients in panel $(<25 \%)$ were associated with lower frequency of shared decision-making with Black patients. Physician age ( $<40$ years) was associated with not discussing race during screening discussions (OR 2.24, 95\% $\mathrm{Cl}$ 1.55-3.23).

CONCLUSIONS: Most academic family physicians do not appropriately inform Black men of increased prostate cancer risk, with younger physicians less likely to discuss race than older physicians. Female physicians, and physicians who see fewer Black patients, are less likely to have shared decision-making conversations with Black patients. This suggests educational efforts for these groups are needed to address health disparities in prostate cancer.

(Fam Med. 2022;54(1):30-7.)

doi: 10.22454/FamMed.2022.474827

D rostate cancer is the most common noncutaneous cancer diagnosed among men in the United States. ${ }^{1}$ It is the second leading cause of cancer mortality for American men, and salient racial disparities exist. ${ }^{2}$ Black men have a prostate cancer incidence ity rate 2.2 times higher than that of White men. ${ }^{3}$ The optimal approach to prostate cancer screening among Black men remains controversial. Though Black men experience a disproportionate burden from prostate cancer morbidity and mortality, there is a lack of prostate cancer screening guidelines specific to Black men. Racial prostate cancer disparities are understood to be multifaceted, involving access to care and screening, biological tumor aspects, and substandard treatment of prostate cancer. ${ }^{4-6}$ Subgroup analyses of studies after the 2012 United States Preventative Services Task Force (USPSTF) recommendation against routine prostate-specific antigen (PSA) screening suggested that the guideline change resulted in decreased rates of PSA-based prostate cancer screening among Black men. White men continued to receive routine PSA-based prostate cancer screening at higher rates than Black men despite the known outcomes disparities. ${ }^{7}$ The detailed 2018 USPSTF recommendations include a new suggestion to inform Black men of their increased risk of dying from prostate cancer compared to the general population. ${ }^{8}$

Educating patients and practitioners about prostate cancer screening is challenging due to frequently evolving guidelines and the different recommendations from different professional medical societies. The USPSTF released a controversial
From Medical University of South Carolina, Charleston, SC (Drs Shungu and Diaz, and Ms Perkins); and Emory University, Atlanta, GA (Dr Kulshreshtha). 
summary statement in 2012 that American men should not receive routine PSA-based screening for prostate cancer. ${ }^{9}$ This position was changed in 2018 with the USPSTF recommendation that all men aged 55-69 years should make a personal decision about screening after being informed about the benefits and risks. ${ }^{8}$ These new recommendations were largely based on data from two large studies that showed that prostate cancer screening does confer a slight mortality benefit, but is associated with several potential harms as well. ${ }^{10,11}$ However, these studies lacked adequate representation from Black and other minority participants.

Prior studies have demonstrated that USPSTF recommendations have the strongest influence on prostate cancer screening practices among a population of mostly nonacademic primary care physicians. ${ }^{12}$ It is currently unknown if and how academic family physicians are approaching prostate cancer screening in general, and specifically with their Black patients. These questions are of significance in the context of known racial disparities in prostate cancer, especially considering the impact that academic family physicians have on educating future generations of physicians. The goal of this study was to describe how academic family physicians are approaching prostate cancer screening in general, and specifically with Black men. Study objectives included assessing current knowledge of USPSTF guidelines, evaluating whether academic family physicians incorporate disparate racial mortality outcomes into their approach to prostate cancer screening, and identifying demographic variables associated with engaging patients in informed decision-making conversations about prostate cancer screening.

\section{Methods}

Data were gathered and analyzed as part of the 2020 Council of Academic Family Medicine's (CAFM) Educational Research Alliance (CERA) survey of practicing family physicians. CAFM is a joint initiative of four major academic family medicine organizations, including the Society of Teachers of Family Medicine, North American Primary Care Research Group, Association of Departments of Family Medicine and Association of Family Medicine Residency Directors. CAFM members were invited to propose survey questions for inclusion into the CERA survey. Approved projects were assigned a CERA Research Mentor to help refine questions. The final draft of survey questions was then modified following pilot-testing.

The American Academy of Family Physicians Institutional Review Board approved this study in January 2020.

We selected participants based on membership type in one of the CAFM organizations. We then limited the pool to exclude program directors, clerkship directors, and department chairs, based on the most recent survey of those groups. Additionally, the survey contained qualifying questions to ensure only practicing physicians were surveyed. Invitations to participate in the study included a personalized greeting and a letter signed by the presidents of each of the four sponsoring organizations with a link to the survey, which was conducted through the online program Survey Monkey. Nonrespondents received five requests to complete the survey; the final request was sent 2 days before the survey was closed. The survey was delivered to a final sample of 3,665 family physicians between January 15, 2020, and March 2, 2020.

In addition to general demographic items that were part of the larger survey, this study included 10 questions addressing the following topics: source of prostate cancer screening information, method of prostate cancer screening, knowledge of USPSTF guidelines, self-reported frequency of shared decision-making conversations around prostate cancer screening, self-reported PSA screening practices, barriers to discussing prostate cancer screening, overall approach to prostate cancer screening in Black and non-Black men, and percentage of patient population that is Black.

\section{Data Analysis}

We conducted analyses using SPSS software, version $25 .{ }^{13}$ We used univariate analysis of frequency distribution for all questions. We conducted bivariate analyses comparing responses to the questions by demographic characteristics (race, gender, age, size of community), using either a Pearson $\chi^{2}$ test or Fisher exact test based on sample sizes. For the purpose of analysis, we stratified gender into binary categories of male and female and we separated age into groups of ages 20-39 years, $40-59$ years, and 60 or more years. We divided the variable for percent of patient panel that is Black into $0 \%-25 \%$ and $26 \%-100 \%$ groups because the majority of physicians had panels with fewer than $25 \%$ Black patients. This $25 \%$ threshold for dichotomization has been previously cited in the literature. ${ }^{14}$ We asked independent questions about prostate cancer screening approach in Black patients and non-Black patients. We conducted $\chi^{2}$ analyses including only the respondents who answered questions for both populations of patients so that statistical significance could be calculated. Finally, we performed both univariate and multivariate analyses for questions pertaining to screening approaches specifically in Black patients. We performed separate logistic regression models for the following four dependent variables: (1) rates of engaging in decision-making conversations, (2) rates of PSA screening, (3) presence of barriers to decision-making conversations, and (4) engaging in race-specific conversations. For each of these models, we included physician age, physician gender, and percentage of Black patients in panel as independent variables and calculated crude odds ratios. These independent variables were selected a priori as factors 
that we hypothesized would impact approach to prostate cancer screening in Black men. We did not include race or ethnicity of the physician in the models due to small sample size. We subsequently adjusted each logistic regression model for physician age, physician gender, and percentage of Black patients in patient panel to calculate adjusted odds ratios. All three independent variables were included in the regression model, regardless of their $P$ value in the crude analyses.

\section{Results}

The overall response rate for the survey was $32.5 \%(1,192 / 3,665)$. Demographics are presented in Table 1 . The overwhelming majority of respondents identified as White $(85.9 \%)$ and non-Latino (94.2\%). Women composed 59\% of the respondents. Almost half of respondents were between the ages of 40 and 59 years $(46.2 \%)$. About $30 \%$ of the physicians surveyed had a patient population that was more than $25 \%$ Black.

Self-reported prostate cancer screening practices are displayed in Table 2. Most physicians (87\%) used the USPSTF as their primary source for prostate cancer screening information. A majority (69.4\%) of respondents screened with PSA alone, while $24.8 \%$ screened with a PSA and digital rectal exam (DRE). Most respondents $(70.1 \%)$ correctly identified the most recent USPSTF prostate cancer screening recommendation (not included in Table 2). There were no significant differences in correct responses by age $(P=.17)$, gender $(P=.10)$, or percentage of Black patients $(P=.72)$. Less than one-third of physicians $(29.2 \%)$ reported they inform Black men aged 55-69 years of their increased risk of developing and dying from prostate cancer as part of routine care. An additional $12.1 \%$ of physicians reported they inform Black men of their increased prostate cancer risks only if the patient introduces the topic. Physicians reported engaging in shared decision-making for prostate cancer screening in about half of eligible men $(50.4 \%$ White men vs $54.8 \%$ of Black men, $P=.01$ ).

\section{Approaches to Prostate Cancer} Screening for Non-Black Patients For non-Black patients, slightly more than half of physicians (50.4\%) engaged in shared decision-making

Table 1: Physician Demographics

\begin{tabular}{|l|c|}
\hline \multicolumn{1}{|c|}{ Physician Variable } & $\mathbf{n ~ ( \% )}$ \\
\hline Race (N=1,143) & $982(85.9)$ \\
White & $102(8.9)$ \\
Asian & $52(4.5)$ \\
Black/African-American & $7(0.6)$ \\
Other & \\
\hline Ethnicity (N=1,165) & $67(5.8)$ \\
Latino & $1,098(94.2)$ \\
Not-Latino & $700(59.0)$ \\
Gender (N=1,186) & $478(40.3)$ \\
Female & $8(0.7)$ \\
Male & \\
Did not disclose & $420(35.4)$ \\
\hline Age, in Years (N=1,188) & $549(46.2)$ \\
20-39 & $219(18.4)$ \\
40-59 & \\
60+ & $792(70.2)$ \\
\hline Percent Patients in Practice Who Are Black (N=1,128) & $336(29.8)$ \\
0\%-25\% & \\
26\%-100\% & \\
\hline
\end{tabular}

conversations about prostate cancer screening at the majority of their preventive visits. The most common response was that $1 \%-25 \%$ of preventive visits involve shared decisionmaking conversations about prostate cancer screening $(34.9 \%)$, and that $1 \%-25 \%$ of patients complete PSA screening (54.9\%). The most commonly-cited barriers to PSA screening conversations were time (31.1\%) and personal feeling that risks outweigh benefits (10.6\%). One-third $(33.7 \%)$ of physicians perceived no barriers to PSA screening discussions.

Age of Physician. Age of physician was not significantly associated with attempts at shared decision-making during preventive visits (Table 3). Younger physicians were more likely to perceive barriers to discussing prostate cancer screening compared to older physicians (age 20-39: 76.6\%, age 40-59: $64.7 \%$, age 60 or more: $51.4 \%, P<.01)$. Younger physicians were more likely to perceive time as a barrier to discussing prostate cancer screening (age 20-39: 34.9\%, age 40-59: $31.4 \%$, age $60: 23.8 \%, P=.02$ ).

Gender of Physician. Male physicians were more likely to attempt shared decision-making at preventive visits than female physicians (Table 3). Male physicians were also more likely than female physicians to report that more than $25 \%$ of their patients completed PSA screening ( $49.3 \%$ vs $36.9 \%, P<.01)$ Female physicians were more likely than male physicians to perceive barriers to discussing prostate cancer screening with patients $(70.7 \%$ vs $60.7 \%$, $P<.01$ )

\section{Approaches to Prostate Cancer} Screening for Black Patients For Black patients, slightly more than half of physicians (54.8\%) engaged in shared decision-making conversations about prostate cancer screening at the majority of their preventive visits. The most common response was that $76 \%-100 \%$ of preventive visits involve shared 
Table 2: Physician Approaches to Prostate Cancer Screening

\begin{tabular}{|c|c|c|c|}
\hline Topic & Answer Choices & \multicolumn{2}{|c|}{ n (\%) } \\
\hline $\begin{array}{l}\text { Primary source of information } \\
\text { guiding physician approach to } \\
\text { prostate cancer screening }\end{array}$ & $\begin{array}{l}\text { USPSTF } \\
\text { UpToDate } \\
\text { American Cancer Society } \\
\text { I do not use a primary source } \\
\text { Other }\end{array}$ & \multicolumn{2}{|l|}{$\begin{array}{l}\mathbf{N}=\mathbf{1 , 1 3 8} \\
990(87 \%) \\
52(4.6 \%) \\
13(1.1 \%) \\
16(1.4 \%) \\
66(5.9 \%) \\
\end{array}$} \\
\hline $\begin{array}{l}\text { Preferred method of prostate } \\
\text { cancer screening }\end{array}$ & $\begin{array}{l}\text { PSA } \\
\text { PSA and digital rectal exam } \\
\text { Digital rectal exam only } \\
\text { Other }\end{array}$ & \multicolumn{2}{|l|}{$\begin{array}{l}\mathbf{N}=\mathbf{1 , 1 3 4} \\
787(69.4 \%) \\
281(24.8 \%) \\
23(2 \%) \\
43(3.8 \%)\end{array}$} \\
\hline $\begin{array}{l}\text { Percentage of preventive visits } \\
\text { that involve attempts at shared } \\
\text { decision-making for prostate } \\
\text { cancer screening among } \\
55-69 \text {-year-old men }{ }^{\mathrm{a}}\end{array}$ & $\begin{array}{l}0 \% \\
1-25 \% \\
26-50 \% \\
51-75 \% \\
76-100 \%\end{array}$ & $\begin{array}{l}\text { Non-Black } \\
\text { Patients } \\
\text { (N=1,129) } \\
28(2.5 \%) \\
394(34.9 \%) \\
138(12.2 \%) \\
236(20.9 \%) \\
333(29.5 \%)\end{array}$ & $\begin{array}{l}\text { Black Patients } \\
\text { (N=1,104) } \\
\\
51(4.6 \%) \\
291(26.4 \%) \\
157(14.2 \%) \\
220(19.9 \%) \\
385(34.9 \%)\end{array}$ \\
\hline $\begin{array}{l}\text { Percentage of } 55-69 \text {-year-old } \\
\text { male patients who complete } \\
\text { screening for prostate cancer } \\
\text { with a PSA }\end{array}$ & $\begin{array}{l}0 \% \\
1 \%-25 \% \\
26 \%-50 \% \\
51 \%-75 \% \\
76 \%-100 \%\end{array}$ & $\begin{array}{l}\text { Non-Black } \\
\text { Patients } \\
\text { (N=1,125) } \\
34(3.0 \%) \\
618(54.9 \%) \\
246(21.9 \%) \\
147(13.1 \%) \\
80(7.1 \%)\end{array}$ & $\begin{array}{l}\text { Black Patients } \\
\text { (N=1,112) } \\
63(5.7 \%) \\
424(38.1 \%) \\
243(21.9 \%) \\
241(21.7 \%) \\
141(12.7 \%)\end{array}$ \\
\hline $\begin{array}{l}\text { Primary barrier to discussing } \\
\text { prostate cancer with } 55-69 \text {-year- } \\
\text { old men }{ }^{c}\end{array}$ & $\begin{array}{l}\text { No barrier } \\
\text { Lack of time } \\
\text { Forget to have conversation } \\
\text { Feel risks outweigh benefits } \\
\text { Lack of tools for discussion } \\
\text { Patient health literacy } \\
\text { Other }\end{array}$ & 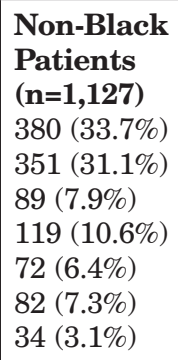 & $\begin{array}{l}\begin{array}{l}\text { Black Patients } \\
(\mathbf{n}=1,115)\end{array} \\
392(35.2 \%) \\
336(30.1 \%) \\
88(7.9 \%) \\
70(6.3 \%) \\
91(8.2 \%) \\
81(7.3 \%) \\
57(5.1 \%)\end{array}$ \\
\hline $\begin{array}{l}\text { Approach to discussing prostate } \\
\text { cancer screening with Black men } \\
\text { aged } 55-69 \text { years }\end{array}$ & $\begin{array}{l}\text { Similar discussion in all races } \\
\text { Inform all Black men of increased risk } \\
\text { Inform Black men who ask of increased risk } \\
\text { Routine PSA screening } \\
\text { Recommend against PSA }\end{array}$ & $\begin{array}{l}\mathbf{N}=\mathbf{1 , 1 1 7} \\
519(46.5 \%) \\
325(29.1 \%) \\
135(12.1 \%) \\
53(4.7 \%) \\
18(1.6 \%)\end{array}$ & \\
\hline
\end{tabular}

Abbreviations: USPSTF, United States Preventive Services Task Force, PSA, prostate-specific antigen test.

a Significant based on $\chi^{2}$ for valid sample $(\mathrm{N}=1,104, P<.001)$.

${ }^{\mathrm{b}}$ Significant based on $\chi^{2}$ for valid sample $(\mathrm{N}=1,109, P<.001)$.

${ }^{\mathrm{c}}$ Significant based on $\chi^{2}$ for valid sample $(\mathrm{N}=1,115)$, Barriers $P<.001$.

decision-making conversations about prostate cancer screening $(34.9 \%)$, and that $1 \%-25 \%$ of patients complete PSA screening (38.1\%). The most commonly-cited barriers to PSA screening conversations with Black patients were time $(30.1 \%)$ and lack of tools to facilitate the discussion (8.2\%). About one-third of physicians $(32.9 \%)$ perceived no barriers to PSA screening.

Age of Physician. There was no significant difference by physician age in the percentage of preventive visits that respondents discussed
PSA screening with Black patients (Table 3). Similar to the findings with non-Black patients, younger physicians were more likely to perceive any barriers to discussing prostate cancer screening with Black men than older physicians (age 2039: $75.9 \%$, age $40-59: 60.5 \%$, age 
Table 3: Percentage of Preventive Visits Where Attempts at Shared Decision-Making Conversations Occur

\begin{tabular}{|c|c|c|c|c|}
\hline Patient Race & Variable & $0 \%-25 \%$ of Visits & $>25 \%$ of Visits & $P$ Value \\
\hline \multirow{3}{*}{ White } & $\begin{array}{l}\text { Physician Gender } \\
\text { Male } \\
\text { Female }\end{array}$ & $\begin{array}{l}145(31.9 \%) \\
275(41.5 \%)\end{array}$ & $\begin{array}{l}309(68.1 \%) \\
388(58.5 \%)\end{array}$ & $<.01$ \\
\hline & $\begin{array}{l}\text { Physician Age (in Years) } \\
20-39 \\
40-59 \\
60+\end{array}$ & $\begin{array}{c}160(40.4 \%) \\
176(34.5 \%) \\
83(39.5 \%)\end{array}$ & $\begin{array}{l}236(59.6 \%) \\
334(65.5 \%) \\
127(60.6 \%)\end{array}$ & .11 \\
\hline & $\begin{array}{l}\text { Patient Panel } \\
\text { 0\%-25\% Black } \\
>25 \% \text { Black }\end{array}$ & $\begin{array}{l}249(37.6 \%) \\
124(37.6 \%)\end{array}$ & $\begin{array}{l}488(62.4 \%) \\
206(62.4 \%)\end{array}$ & .99 \\
\hline \multirow{3}{*}{ Black } & $\begin{array}{l}\text { Physician Gender } \\
\text { Male } \\
\text { Female }\end{array}$ & $\begin{array}{l}116(26.1 \%) \\
224(34.6 \%)\end{array}$ & $\begin{array}{l}328(73.9 \%) \\
242(65.4 \%)\end{array}$ & $<.01$ \\
\hline & $\begin{array}{l}\text { Physician Age (in Years) } \\
20-39 \\
40-59 \\
60+\end{array}$ & $\begin{array}{c}130(33.7 \%) \\
142(28.0 \%) \\
67(33.3 \%)\end{array}$ & $\begin{array}{l}256(66.3 \%) \\
362(71.8 \%) \\
134(66.7 \%)\end{array}$ & .15 \\
\hline & $\begin{array}{l}\text { Patient Panel } \\
\text { 0\%-25\% Black } \\
>25 \% \text { Black }\end{array}$ & $\begin{array}{c}250(32.8 \%) \\
88(27.0 \%)\end{array}$ & $\begin{array}{l}512(73.6 \%) \\
238(73.0 \%)\end{array}$ & .05 \\
\hline
\end{tabular}

60 or older: $55.0 \%, P<.01)$. Younger physicians were also more likely to perceive time as a barrier to discussing prostate cancer screening with Black patients age 20-39: $35.9 \%$, age 40-59: $28.3 \%$, age 60: $24.2 \%, P<.01$ ). Younger physicians were more likely to have a similar prostate cancer screening conversation with patients of all races (age 20-39: $57.4 \%$, age 40-59: $42.2 \%$, age 60 or older: $36.2 \%$, $P<.01)$. Conversely, older physicians were more likely to inform Black men of their increased risk of dying from prostate cancer as part of routine care (age 20-39: $20.2 \%$, age 40-59: $32.9 \%$, age 60 or older $36.6 \%$, $P<.01$ ).

Gender of Physician. Male physicians were more likely than female physicians to attempt shared decision-making conversations during preventive visits with Black men (Table 3). Male physicians were also more likely than female physicians to report that more than $25 \%$ of their Black patients complete PSA screening $(60.8 \%$ vs $52.9 \%, P<.01)$. Female physicians $(68.1 \%)$ were more likely than male physicians $(60.7 \%)$ to perceive any barriers to discussing prostate cancer screening with Black patients $(P=.01)$. Male physicians were also more likely than female physicians to inform Black men of their increased prostate cancer risk as part of routine care $(33.7 \%$ vs $26.1 \%, P<.01)$.

\section{Physician Patient Population}

There was no significant difference in the frequency of prostate cancer screening discussions between physicians who saw larger proportions of Black patients and those who saw fewer Black patients (Table 3). Physicians who served populations that were more than $25 \%$ Black were more likely than those who saw fewer Black patients to report that more than $25 \%$ of their patients completed PSA screening $(63.0 \%$ vs $53.4 \%, P<.01)$. Physicians who served panels composed of more than $25 \%$ Black patients were more likely to inform Black men of their increased prostate cancer risk as part of routine care, though this did not reach statistical significance (32.6\% vs $27.6 \%, P=.09)$.

\section{Logistic Regression}

We conducted logistic regression analyses for each question that assessed approach to prostate cancer screening specifically in Black men. Crude and adjusted odds ratios are presented in Table 4 . In terms of gender, female physicians were less likely than male physicians to report that their preventive visits with Black men involve attempts at shared decision-making (adjusted $\mathrm{OR}=0.63,95 \%$ CI, 0.48-0.83). Compared to physicians aged 60 and older, physicians aged 20-39 (adjusted $\mathrm{OR}=2.4195 \% \mathrm{CI}, 1.65-3.50$ ) were more likely to perceive barriers to discussing prostate cancer screening with Black men. Physicians aged 2039 (adjusted OR=2.24, 95\% CI, 1.553.23) were also more likely than physicians aged 60 and older to exclude race from decision-making discussions. Physicians with more than $25 \%$ of Black patients in their panels were more likely to attempt shared decision-making conversations with Black men (adjusted OR=1.37, 95\% CI, 1.03-1.84), and reported that their Black patients were more likely to complete PSA screening (adjusted $\mathrm{OR}=1.59$, CI, 1.21-2.09).

\section{Discussion}

Our study survey is the first to provide data about prostate cancer screening practices among academic 
Table 4: Multivariable Logistic Regression for Effect of Physician Age, Gender, and Percentage of Black Patients on Prostate Cancer Screening Approach

\begin{tabular}{|c|c|c|c|}
\hline Approach & Variable & $\begin{array}{l}\text { Crude Odds Ratio } \\
\text { (95\% Confidence } \\
\text { Interval) }\end{array}$ & $\begin{array}{l}\text { Adjusted Odds Ratio* } \\
\text { (95\% Confidence } \\
\text { Interval) }\end{array}$ \\
\hline $\begin{array}{l}\text { Reporting }>25 \% \text { of preventive visits } \\
\text { with Black men aged } 55-69 \text { years } \\
\text { involve attempts at shared decision- } \\
\text { making }\end{array}$ & $\begin{array}{l}\text { Age (in Years) } \\
20-39 \\
40-59 \\
60+(\text { ref) } \\
\text { Gender } \\
\text { Male (ref) } \\
\text { Female } \\
\text { Percentage of Black Patients } \\
\text { in Panel } \\
0 \%-25 \% \text { (ref) } \\
26 \%-100 \%\end{array}$ & $\begin{array}{l}0.98(0.69-1.41) \\
1.27(0.90-1.81) \\
-- \\
-- \\
0.67 * *(0.51-0.87) \\
-- \\
1.32(0.99-1.32)\end{array}$ & $\begin{array}{l}1.16(0.79-1.69) \\
1.41(0.98-2.02) \\
-- \\
-- \\
0.63 * *(0.48-0.83) \\
-- \\
1.37 * *(1.03-1.84)\end{array}$ \\
\hline $\begin{array}{l}\text { Reporting }>25 \% \text { of Black men aged } \\
55-69 \text { years undergo prostate-specific } \\
\text { antigen screening }\end{array}$ & $\begin{array}{l}\text { Age (in Years) } \\
20-39 \\
40-59 \\
60+\text { (ref) } \\
\text { Gender } \\
\text { Male (ref) } \\
\text { Female } \\
\text { Percentage of Black Patients } \\
\text { in Panel } \\
0 \%-25 \% \text { (ref) } \\
26 \%-100 \%\end{array}$ & $\begin{array}{l}0.54 * *(0.38-0.76) \\
0.93(0.66-1.30) \\
-- \\
-- \\
0.72 * *(0.57-0.92) \\
-- \\
1.50 * *(1.15-1.95)\end{array}$ & $\begin{array}{l}0.58 * *(0.40-0.83) \\
0.98(0.69-1.37) \\
-- \\
-- \\
0.78(0.60-1.00) \\
-- \\
1.59 * *(1.21-2.09)\end{array}$ \\
\hline $\begin{array}{l}\text { Reporting barriers related to } \\
\text { discussing prostate cancer screening } \\
\text { in Black men aged 55-69 years }\end{array}$ & $\begin{array}{l}\text { Age (in Years) } \\
20-39 \\
40-59 \\
60+\text { (ref) } \\
\text { Gender } \\
\text { Male (ref) } \\
\text { Female } \\
\text { Percentage of Black Patients } \\
\text { in Panel } \\
0 \%-25 \% \text { (ref) } \\
26 \%-100 \%\end{array}$ & $\begin{array}{l}2.56 * *(1.79-3.67) \\
1.25(0.90-1.74) \\
-- \\
-- \\
1.39 * *(1.08-1.78) \\
-- \\
1.15(0.88-1.52)\end{array}$ & $\begin{array}{l}2.41 * *(1.65-3.50) \\
1.21(0.87-1.69) \\
-- \\
-- \\
1.18(0.91-1.54) \\
-- \\
1.09(0.82-1.44)\end{array}$ \\
\hline $\begin{array}{l}\text { Reporting similar PSA risk/benefit } \\
\text { discussions with patients regardless } \\
\text { of race }\end{array}$ & $\begin{array}{l}\text { Age (in Years) } \\
20-39 \\
40-59 \\
60+(\text { ref) } \\
\text { Gender } \\
\text { Male (ref) } \\
\text { Female } \\
\text { Percentage of Black Patients } \\
\text { in Panel } \\
0 \%-25 \% \text { (ref) } \\
26 \%-100 \%\end{array}$ & $\begin{array}{l}2.33^{* *}(1.64-3.31) \\
1.29(0.92-1.82) \\
-- \\
-- \\
1.35^{* *}(1.05-1.73) \\
-- \\
0.80(0.62-1.05)\end{array}$ & $\begin{array}{l}2.24 * *(1.55-3.23) \\
1.24(0.88-1.76) \\
-- \\
-- \\
1.18(0.91-1.53) \\
-- \\
0.75^{* *}(0.57-0.99)\end{array}$ \\
\hline
\end{tabular}

Abbreviation: PSA, prostate-specific antigen.

*Model adjusted for age, gender, percent of black patients in panel.

**Significant at $P<.05$.

family medicine physicians. We found that older physicians were more likely to engage both Black and White men in shared decision-making conversations about prostate cancer screening and were less likely to perceive barriers to these discussions than younger physicians. Our findings contrast with two studies using 2008 data that did not consider patient race, but found that younger physicians were just as skilled, and more likely to engage in shared decision-making about prostate cancer screening than older physicians. ${ }^{15}$ It is possible that our findings differ from previous studies due to changes over time in the USPSTF 
recommendations. Specifically, the 2012 through 2018 USPSTF recommendation against routine prostate cancer screening may have limited trainee education on prostate cancer screening. Our findings suggest the need to focus educational efforts on improving the self-efficacy of trainees to engage men in informed decision-making conversations about prostate cancer screening.

We also found that female physicians are less likely to engage both Black and White men in shared decision-making prostate cancer screening conversations. Previous studies that did not consider the race of the patient reported similar findings that male physicians feel more comfortable discussing prostate cancer screening than female physicians. ${ }^{16,17}$ Other studies have found no difference in rates of PSA testing based on physician gender. ${ }^{18,19}$ Future work should investigate what factors impede or facilitate female physician comfort with prostate cancer screening discussions in order to guide educational strategies.

We found that only $29.1 \%$ of physicians routinely inform Black men of their increased prostate cancer risk, which is notable given that the USPSTF suggests this as best practice. Again, numerous changes to the USPSTF recommendations over the past decade may contribute to this low percentage. Given the well-documented racial disparities in prostate cancer incidence and mortality, it is paramount that future prostate cancer screening education efforts incorporate racial disparities. Physicians and trainees should be well versed in racial disparities in prostate cancer outcomes and incorporate this into their informed decision-making conversations. Also interesting was the finding that older physicians are more likely to discuss racial prostate cancer disparities with Black patients, as compared to younger physicians. This is the first study to our knowledge that evaluates whether physician age impacts the inclusion of race in prostate cancer screening discussions. Further study is needed to understand how and if academic physicians are educating learners about racial prostate cancer disparities as a component of informed decision-making.

Finally, our finding that physicians who cared for higher proportions of Black patients were more likely to engage in shared decisionmaking conversations with them may be explained by physicians with lower proportions of Black patients having less proficiency with these conversations or placing a lower value on them. Conversely, physicians who do not engage in shared decision-making conversations with Black patients may end up with smaller panels of Black patients because these patients choose to see other physicians. In either case, this finding builds on previous literature that clinical exposure to racial minorities and cross-cultural experiences improves likelihood of practicing in diverse communities and providing culturally appropriate care. ${ }^{20-23}$ This finding stresses the importance of learners participating in clinical encounters with Black men. Training sites lacking significant numbers of Black patients should make targeted efforts either in person or virtually to educate learners about approaching prostate cancer screening in Black men.

Our study had a number of limitations. We assessed self-reported behaviors of physicians, which is subject to biases such as recall and response bias. This was an efficient method for collecting data from a geographically diverse sample of academic physicians. Future studies could evaluate the accuracy of self-reported prostate cancer screening practices and observed behaviors. Secondly, the survey's low response rate could reflect selection bias that impacts results. Given that the survey was distributed as a general membership survey and not a prostate cancer screening survey, any selection bias should not be related directly to attitudes about prostate cancer screening. We did not conduct analyses based on race of the physician due to very small numbers of non-White physicians. Studies conducted prior to the most recent USPSTF guidelines found that nonacademic Black physicians were more likely to discuss prostate cancer screening with Black patients and were more likely to screen Black patients for prostate cancer as well. ${ }^{24}$

\section{Conclusion}

Prostate cancer is a prevalent disease that disproportionately kills Black men, yet academic family physicians are not routinely informing their Black male patients about increased prostate cancer risk. Younger physicians, women physicians, and physicians who see fewer Black patients are more likely to have suboptimal approaches to prostate cancer screening in Black men. The academic medical community must focus educational efforts on educating family physicians and trainees about facilitating informed decision-making conservations around prostate cancer screening, especially in light of racially disparate outcomes.

ACKNOWLEDGMENTS: The authors thank Carole Berini (MUSC) for her assistance with data analysis.

CORRESPONDING AUTHOR: Address correspondence to Nicholas Shungu, Medical University of South Carolina, Department of Family Medicine, 5 Charleston Center Dr, Ste 263, MSC 192, Charleston SC, 29425. 843-9855500. Fax: 8439850451.

\section{References}

1. Siegel RL, Miller KD, Jemal A. Cancer statistics, 2015. CA Cancer J Clin. 2015;65(1):5-29. doi:10.3322/caac. 21254

2. US Cancer Statistics Working Group. United States Cancer Statistics: 1999-2014 Incidence and Mortality Web-based Report. Atlanta, GA: Centers for Disease Control and Prevention. Published 2017. Accessed November 12, 2020. http://www.cdc.gov/uscs.

3. Cancer Statistics Center: Prostate. American Cancer Society. . Accessed November 12 , 2020. https://cancerstatisticscenter.cancer. org/?_ga=2.35330471.761582147.16033050791987363365.1603305079\#!/cancer-site/Prostate

4. Krimphove MJ, Cole AP, Fletcher SA, et al. Evaluation of the contribution of demographics, access to health care, treatment, and tumor characteristics to racial differences in survival of advanced prostate cancer. Prostate Cancer Prostatic Dis. 2019;22(1):125-136. doi:10.1038/ s41391-018-0083-4 
5. Friedlander DF, Trinh QD, Krasnova A, et al. Racial disparity in delivering definitive therapy for intermediate/high-risk localized prostate cancer: the impact of facility features and socioeconomic characteristics. Eur Urol. 2018;73(3):445-451. doi:10.1016/j. eururo.2017.07.023

6. Krimphove MJ, Fletcher SA, Cole AP, et al. Quality of care in the treatment of localized intermediate and high risk prostate cancer at minority serving hospitals. J Urol. 2019;201(4):735-741. doi:10.1016/j. juro.2018.10.024

7. Gilligan T, Wang PS, Levin R, Kantoff PW, Avorn J. Racial differences in screening for prostate cancer in the elderly. Arch Intern Med. 2004;164(17):1858-1864. doi:10.1001/ archinte.164.17.1858

8. Grossman DC, Curry SJ, Owens DK, et al; US Preventive Services Task Force. Screening for prostate cancer: US Preventive Services Task Force recommendation statement. JAMA. 2018;319(18):1901-1913. doi:10.1001/ jama.2018.3710

9. Moyer VA; U.S. Preventive Services Task Force. Screening for prostate cancer: US Preventive Services Task Force recommendation statement. Ann Intern Med. 2012;157(2):120-134. doi:10.7326/0003-4819-157-2-201207170-00459

10. Andriole GL, Crawford ED, Grubb RL III, et al; PLCO Project Team. Prostate cancer screening in the randomized Prostate, Lung, Colorectal, and Ovarian Cancer Screening Trial: mortality results after 13 years of follow-up. J Natl Cancer Inst. 2012;104(2):125-132. doi:10.1093/ jnci/djr500
11. Schröder FH, Hugosson J, Roobol MJ, et al; ERSPC Investigators. Prostate-cancer mortality at 11 years of follow-up. N Engl J Med. 2012;366(11):981-990. doi:10.1056/NEJMoa1113135

12. Tasian GE, Cooperberg MR, Cowan JE, et al. Prostate specific antigen screening for prostate cancer: knowledge of, attitudes towards, and utilization among primary care physicians. Urol Oncol. 2012;30(2):155-160. doi:10.1016/j. urolonc.2009.12.019

13. IBM SPSS Statistics for Windows. Version 25.0 Armonk, NY: IBM Corp; 2021.

14. Li C, West-Strum D. Patient panel of underserved populations and adoption of electronic medical record systems by office-based physicians. Health Serv Res. 2010;45(4):963-984 doi:10.1111/j.1475-6773.2010.01113.x

15. Ross LE, Hall IJ, Howard DL, Rim SH, Richardson LC. Primary care physicians beliefs about prostate-specific antigen evidence uncertainty, screening efficacy, and test use. J Nat Med Assoc. 2018;110(5):491-500. doi:10.1016/j. jnma.2017.12.007

16. Engler J, Dahlhaus A, Güthlin C. The readiness of German GPs to recommend and conduct cancer screening is associated with patient-physician gender concordance. Results of a survey. Eur J Gen Pract. 2017;23(1):11-19. doi:10.1080/13814788.2016.1240166

17. Lurie N, Margolis K, McGovern PG, Mink P. Physician self-report of comfort and skill in providing preventive care to patients of the opposite sex. Arch Fam Med. 1998;7(2):134-137. doi:10.1001/archfami.7.2.134
18. Fang MC, McCarthy EP, Singer DE. Are patients more likely to see physicians of the same sex? Recent national trends in primary care medicine. Am J Med. 2004;117(8):575-581. doi:10.1016/j.amjmed.2004.03.043

19. Voss JD, Schectman JM. Prostate cancer screening practices and beliefs. J Gen Intern Med. 2001;16(12):831-837. doi:10.1046/j.15251497.2001.10133.x

20. Min-Yu Lau P, Woodward-Kron R, Livesay K, Elliott K, Nicholson P. Cultural respect encompassing simulation training: being heard about health through broadband. J Public Health Res. 2016;5(1):657.

21. Sopoaga F, Zaharic T, Kokaua J, Covello S. Training a medical workforce to meet the needs of diverse minority communities. BMC Med Educ. 2017;17(1):19. doi:10.1186/s12909017-0858-7

22. Laraque-Arena D, Frintner MP, Cull WL. Underserved areas and pediatric resident characteristics: is there reason for optimism? Acad Pediatr. 2016;16(4):401-410. doi:10.1016/j. acap.2015.10.004

23. Frintner MP, Mendoza FS, Dreyer BP, Cull WL, Laraque D. Resident cross-cultural training, satisfaction, and preparedness. Acad Pediatr. 2013;13(1):65-71. doi:10.1016/j. acap.2012.10.005

24. Ross LE, Hall IJ. African American primary care physicians' prostate cancer screening practices. J Prim Care Community Health. 2014;5(1):36-43. doi:10.1177/2150131913507454 